\title{
Label-free Voltammetric Immunosensor for Prostate Specific Antigen Detection
}

\author{
Nélia Oliveira, ${ }^{[\mathrm{a}]}$ Estefanía Costa-Rama, ${ }^{[\mathrm{a}]}$ Subramanian Viswanathan, ${ }^{*[\mathrm{~b}]}$ Cristina Delerue-Matos, ${ }^{[\mathrm{a}]}$ \\ Lourdes Pereira, ${ }^{[c]}$ and Simone Morais*[a]
}

\begin{abstract}
This work describes a sensitive voltammetric immunosensor for label-free electroanalysis of the prostate specific antigen (PSA), the main biomarker of prostate cancer. A gold electrode was firstly modified with the optimum self-assembled monolayer (SAM), 1,6hexanedithiol, followed by the subsequent adsorption of gold nanoparticles (AuNPs) and, then, the monoclonal antibody to recognize PSA was immobilized. The influence of the most significant experimental variables (SAM type and incubation time, AuNPs deposition, antibody concentration and bovine serum albumin immobilization)
\end{abstract}

on the biosensor response was studied by microscopy and voltammetry techniques. The electroanalytical detection was based on the interaction between PSA antibody and PSA via square-wave voltammetry using ferrocyanide/ ferricyanide as electrochemical redox indicator. Using the proposed immunosensor, PSA was specifically detected within the linear range between 0.2 and $200 \mathrm{ng} \mathrm{mL}^{-1}$ with $0.01 \mathrm{ng} \mathrm{mL}^{-1}$ as limit of detection. The immunosensor allows accurate, reproducible and sensitive $(22.7 \%$ reduction $\mathrm{mLng}^{-1}$ ) detection in a concentration range useful for clinical purposes.

Keywords: Electrochemical immunosensor - Self-assembled monolayer • Gold nanoparticles • Cancer biomarker • Prostate specific antigen

\section{Introduction}

Prostate cancer is still a clinical issue considering that it is the second most common cancer in men and the fifth leading cause of cancer-related mortality among men with an estimate of 307000 deaths in 2012 [1,2]. The symptoms mostly appear in advanced phases of the disease; therefore, early diagnostic is undoubtedly desire to reduce evolution risks and malignancy. Prostate specific antigen (PSA) is a serine protease, being one of the most prevalent proteins in semen; it can move into the blood stream through the basal cells and the basement membrane [3]. Blood PSA concentration is significantly augmented in prostate cancer patients, because of the disorder of the prostate gland [3-5]. PSA is used extensively as a prostate cancer biomarker with the aim of screen, diagnose, follow-up the response to treatment and detection of recurrence after definite therapy [4-6]. A value of PSA higher than the cut-off value $\left(2.5-4 \mathrm{ng} \mathrm{mL}^{-1}\right)$ indicates high probability of prostate cancer $[6,7]$.

In recent years, immunosensors have been appearing as a promising approach for biomarker quantification. Among the different detection strategies, electrochemical immunosensors have attracted much attention because they combine the specificity and sensitivity of immunoassay procedures, and the simplicity, low cost, as well as the automatization and miniaturization potential of the electrochemical measurement systems [4,8-10]. Most of the developed immunosensors use a label to obtain the analytical response. However, currently label-free immunosensors are a true alternative since they provide rapid and accurate analyses while reducing the preparation steps and, therefore, also improving the analytical precision $[4,11]$. A critical aspect for the successful development of an electrochemical immunosensor is the antibody immobilization: the key issue is to immobilize antibodies at an appropriate concentration, maintain their bioactivity and promote their immobilization with suitable orientation to interact favorably with its target antigen $[12,13]$.

Self-assembly provides a simple method to functionalize metallic electrode surfaces with organic molecules, which have free anchor groups (thiols, disulfides, amines, silanes, or acids), by their spontaneous organization onto the metal surface $[14,15]$. Thus, self-assembled monolayers (SAMs) have been extensively applied as the basis for electrochemical biosensor development, since they provide well-ordered assemblies strongly chemisorbed on substrates (electrodes) that improved the adsorption

[a] N. Oliveira, E. Costa-Rama, C. Delerue-Matos, S. Morais REQUIMTE/LAQV, Instituto Superior de Engenharia do Porto, Instituto Polit?cnico do Porto, Rua Dr. Ant?nio Bernardino de Almedia 431, 4200-072 Porto, Portugal E-mail: sbm@isep.ipp.pt

[b] S. Viswanathan

Department of Industrial Chemistry, Alagappa University, Karaikudi-630003, Tamilnadu, India E-mail: rsviswa@gmail.com

[c] L. Pereira

Department of Medical Sciences, CICECO-Aveiro Institute of Materials, University of Aveiro, Campus Santiago 3810-193 Aveiro, Portugal 
capacity and stability of immobilized components [14,15]. SAMs present several advantages such as easy formation, flexibility in functional control by changing the tail group and needed of low amount of biomolecules for immobilization $[14,16]$. Moreover, SAMs can be coupled with gold nanoparticles (AuNPs) [13,16-18], which present unique physico-chemical properties, such as high surface/volume ratio, high stability and good biological compatibility, making themselves an ideal base for biosensing platform $[12,19,20]$. AuNPs also display excellent conduction characteristics and are easy to functionalize; AuNPs surface can be coated with an antibody by simple adsorption maintaining the bioactivity of the adsorbed biomolecules [21-24]. Thus, AuNPs are particularly interesting from an electroanalytical point of view to couple interface biological recognition reactions with electronic signal transduction $[19,20,25]$. Moreover, AuNPs as sensing platform can not only immobilize a higher amount of biomolecule, but as well speed up the electron transfer improving the analytical signal $[12,19]$.

Lately, a lot of immunoassay methods related to PSA detection have been reported including enzyme-linked immunosorbent-assays (ELISA) [26], electrochemical immunoassays [24,27-29], chemiluminescent immunoassays [30] and bioluminescent immunoassay [31]. Although those methods are reliable, most of them require long measurement procedures, high costs, complex equipment, highly qualified personnel and are not appropriate for massive decentralized assays. Therefore, nowadays it is still a challenge to develop simple, low-cost and appropriate detection methods for sensitive determination of PSA levels [6,32]. In this work, a simple and sensitive nanostructured label free immunosensor for PSA quantification is proposed. The sensor consisted of AuNPs deposited on the previously 1,6-hexanedithiol (HDT) modified gold electrode (HDT/Au electrode), followed by antibody adsorption. The biosensor construction and the assessment of the immune reaction between the modified electrode and the biomarker were characterized by cyclic voltammetry $(\mathrm{CV})$ and square-wave voltammetry (SWV).

\section{Experimental}

\subsection{Reagents and Solutions}

Absolute ethanol and hydrochloric acid ( $\mathrm{HCl})(37 \%)$ were purchased from Carlo Erba Reagents. Sulfuric acid $\left(\mathrm{H}_{2} \mathrm{SO}_{4}\right)(96 \%)$, hydrogen peroxide $\left(\mathrm{H}_{2} \mathrm{O}_{2}\right)(30 \%)$ and sodium chloride $(\mathrm{NaCl} ; 99 \%)$ were delivered by PanReac AppliChem. Alumina solutions $\left(\gamma-\mathrm{Al}_{2} \mathrm{O}_{3}\right) \quad 0.3 \mu \mathrm{m}$ and $0.05 \mu \mathrm{m}$ were obtained from Gravimeta. Glycine, potassium hexacyanoferrate (III) $\left(\mathrm{K}_{3} \mathrm{Fe}(\mathrm{CN})_{6}\right)$, potassium hexacyanoferrate (II) trihydrate $\left(\mathrm{K}_{4} \mathrm{Fe}(\mathrm{CN})_{6} \cdot 3 \mathrm{H}_{2} \mathrm{O}\right)$, potassium hydrogen phosphate $\left(\mathrm{KHPO}_{4}\right)$, potassium dihydrogen phosphate $\left(\mathrm{KH}_{2} \mathrm{PO}_{4}\right)$, trisodium citrate dehydrate, glutaraldehyde, 1,6-hexanedithiol (HDT), cystamine (CYS), 2mercaptoethanol (ME), 3-mercaptopropionic acid (MPA) solution, N-hydroxysuccinimide (NHS), N-(3-Dimethyla-
minopropyl)-N-ethylcarbodiimide hydrochloride (EDC) and gold(III) chloride solution $(30 \%)\left(\mathrm{HAuCl}_{4}\right)$ were purchased from Sigma-Aldrich. Bovine serum albumin fraction V (BSA) was obtained from Acros Organics. Natural human prostate specific antigen protein (PSA) (ab78528) and anti-prostate specific antigen (anti-PSA) mouse monoclonal antibody [5A6] (ab10185) were purchased from Abcam. Ultrapure water used throughout this work was obtained from a Milli-Q Simplicity 185 system (Merck Millipore). BSA, PSA antibody and PSA solutions were prepared in $0.1 \mathrm{M}$ PBS pH 7.4 buffer.

\subsection{Electrochemical Measurements}

Electrochemical measurements were performed with an Autolab PSTAT 12 potentiostat/galvanostat (Metrohm Autolab B.V.) controlled by a computer through the Autolab GPES software version 4.9. A conventional three-electrode cell was used for all electrochemical measurements: a polycrystalline gold electrode, BASiMF2014 , with a surface area of $2.0 \mathrm{~mm}^{2}$ and a diameter of $1.6 \mathrm{~mm}$, as a working electrode; platinum as counterelectrode; and a $\mathrm{Ag}|\mathrm{AgCl}| 3 \mathrm{M} \mathrm{KCl}$ reference electrode to which all potentials are referred.

SWV and $\mathrm{CV}$ were performed using $\mathrm{Fe}(\mathrm{CN})_{6}{ }^{3-14-}$ as electroactive indicator at a concentration of $10 \mathrm{mM}$ in 0.1 M PBS solution ( $\mathrm{pH}$ 7.4). SWV measurements were obtained varying the potential from 0.6 to $-0.2 \mathrm{~V}$ at a scan rate of $200 \mathrm{mV} \cdot \mathrm{s}^{-1}$. The optimal SWV parameters were a frequency of $50 \mathrm{~Hz}$, amplitude of $20 \mathrm{mV}$ and scan increment of $4 \mathrm{mV}$. CV measurements were performed at $50 \mathrm{mV} \mathrm{s}^{-1}$ in the same potential range as SWV.

\subsection{Immunosensor Development}

\subsubsection{Pretreatment of Gold Disk Electrode}

The surface of the bare $\mathrm{Au}$ electrode was polished repeatedly with 0.3 and $0.05 \mu \mathrm{m}$ alumina powder on microfiber cloth. Afterwards, the electrode was rinsed with water and ultrasonically cleaned in absolute ethanol. Then, the electrode surface was cleaned by immersion in piranha solution $\left(\mathrm{H}_{2} \mathrm{O}_{2}: \mathrm{H}_{2} \mathrm{SO}_{4}, 1: 3 \mathrm{v} / \mathrm{v}\right)$ for $5 \mathrm{~min}$ at room temperature (RT). After that, the electrode was rinsed with water, and cycled 25 times from $-0.2 \mathrm{~V}$ to $1.6 \mathrm{~V}$ in $0.5 \mathrm{M} \mathrm{H}_{2} \mathrm{SO}_{4}$ solution at a scan of $100 \mathrm{mV} / \mathrm{s}$. Finally, a cleaning step was performed by $\mathrm{CV}$, cycling 25 times from $-0.2 \mathrm{~V}$ to $1.4 \mathrm{~V}$ in $0.5 \mathrm{M} \mathrm{KOH}$ at a scan of $100 \mathrm{mV} / \mathrm{s}$. After a washing step with water, the electrode was ready to be modified.

\subsubsection{Modification with Self-assembled Monolayer}

Five different SAMs were studied to modify the gold electrode. In order to perform the modification, the $\mathrm{Au}$ electrode was immersed, for $12 \mathrm{~h}$ at $\mathrm{RT}$, in ethanol solutions of CYS (0.1 M), CYS + ME (0.1 M of each one), MPA (1 mM), MPA + ME (1 mM of each one) and HDT 
$(1 \mathrm{mM})$. After rinsing with water to remove any unbound molecules, the CYS-modified electrodes were immersed in a $3 \%$ glutaraldehyde solution for $30 \mathrm{~min}$, while the MPAmodified electrodes were immersed in an EDC/NHS solution $(0.02 \%, w / v$, of each one in PBS pH 7.4). For the HDT-modified gold electrode (HDT/Au), just a washing step with ethanol and water was required.

After selection of the best SAM-modified electrode to construct the immunosensor, the incubation time for the SAM formation at RT was optimized varying from 1 to $2 \mathrm{~h}$.

\subsubsection{Synthesis of Gold Nanoparticles and Electrode Modification}

AuNPs were synthesized according to the Turkevich method [1]. First, $20 \mu \mathrm{L}$ of $\mathrm{HAuCl}_{4}$ solution were mixed with $20 \mathrm{~mL}$ water. This mixture was heated up, while being stirred, until boiling. Then, $2 \mathrm{~mL}$ of trisodium citrate $0.01 \%(\mathrm{w} / \mathrm{v})$ were added in two times $(2 \times 1 \mathrm{~mL})$. The mixture was stirred until the color of solution was changed to wine-red. The solution was then cooled to RT. The synthetized AuNPs were characterized by UV-Visible spectroscopy (UV 1800-Shimadzu, Germany), laser doppler velocimetry and dynamic light scattering (Zetasizer Nano ZS; Malvern Ltd, UK). To immobilize the AuNPs on the surface of the HDT/Au electrode, it was immersed in the AuNPs solution for $2 \mathrm{~h}$. After washing with water and PBS buffer (0.1 M, pH 7.4), the AuNPs/HDT/Au electrode was ready to immobilize the PSA antibody. The bare $(\mathrm{Au})$ and the modified electrodes were characterized by scanning electron microscopy (SEM; FEI Quanta 400FEGESEM/EDAX Genesis X4M) coupled with an energy dispersive spectrometer (EDS; EDAX Pegasus $\mathrm{X} 4 \mathrm{M})$.

\subsubsection{Antibody Immobilization}

Antibodies against PSA were immobilized by adsorption depositing $20 \mu \mathrm{L}$ of anti-PSA solution (prepared in $0.1 \mathrm{M}$ PBS pH 7.4 buffer) onto the AuNPs/HDT/Au electrode and placing it to incubate at $4{ }^{\circ} \mathrm{C}$ for $12 \mathrm{~h}$. Then, the anti$\mathrm{PSA} / \mathrm{AuNPs} / \mathrm{HDT} / \mathrm{Au}$ electrode was rinsed with a $0.1 \mathrm{M}$ glycine solution. At last, in order to block the remaining adsorption-reactive sites, the anti-PSA/AuNPs/HDT/Au electrode was immersed in a $20 \mu \mathrm{g} \mathrm{mL}^{-1}$ BSA solution (prepared in $0.1 \mathrm{M}$ PBS pH 7.4 buffer) for $5 \mathrm{~min}$ at $4{ }^{\circ} \mathrm{C}$. Then, the BSA/anti-PSA/AuNPs/HDT/Au was rinsed with PBS solution.

\subsubsection{Electrochemical Detection of PSA}

In order to perform the PSA detection, $10 \mu \mathrm{L}$ of PSA solution prepared in 0.1 M PBS $\mathrm{pH} 7.4$ buffer were drop casted onto the BSA/anti-PSA/AuNPs/HDT/Au electrode. After a $12 \mathrm{~h}$ incubation step at $4{ }^{\circ} \mathrm{C}$, the SWV measurements were carried out.
The cathodic peak current reduction $\left(\mathrm{I}_{\mathrm{p}} \mathrm{R}(\%)\right)$ was employed to obtain PSA analytical curves. $\mathrm{I}_{\mathrm{p}} \mathrm{R}(\%)$ was calculated with the equation (1):

$\mathrm{I}_{\mathrm{p}} \mathrm{R}(\%)=\left(1-\left(\mathrm{I}_{\mathrm{p}} / \mathrm{I}_{\mathrm{p}}{ }^{0}\right)\right) \times 100$

where $I_{p}{ }^{0}$ and $I_{p}$ were the peak current intensities of $\mathrm{Fe}(\mathrm{CN})_{6}{ }^{3-14-}$ (used as electroactive indicator at a concentration of $10 \mathrm{mM}$ in $0.1 \mathrm{M}$ PBS solution $\mathrm{pH}=7.4$ ) before and after the incubation with PSA, respectively.

\subsubsection{Reutilization of the Immunosensor}

In order to reuse the immunosensor, after PSA detection the PSA/BSA/anti-PSA/AuNPs/HDT/Au electrode was immersed in $0.1 \mathrm{M}$ glycine- $\mathrm{HCl}$ solution $\mathrm{pH} 3$ at $4^{\circ} \mathrm{C}$ for 20 minutes. Then, the immunosensor, after a rinsing step with PBS, was ready for a new PSA determination.

\section{Results and Discussion}

\subsection{Immunosensor Development}

In Figure 1, the different steps concerning the development of the developed PSA immunosensor are schematically illustrated. In this section, optimization studies of the different variables involved in the immunosensor construction are presented.

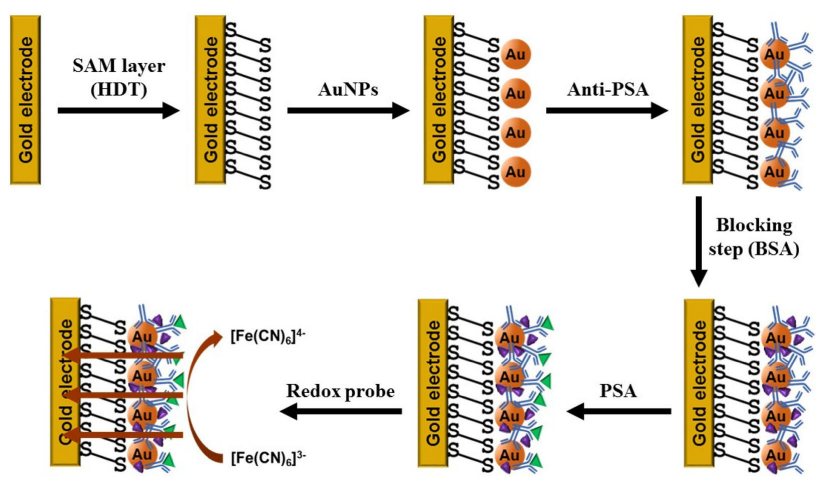

Fig. 1. Schematic representation of the different steps needed for the immunosensor construction.

\subsubsection{Self-assembled Monolayer Formation}

First, five different SAMs (CYS (0.1 M), CYS + ME (0.1 M each one), MPA (1 mM), MPA + ME (1 mM each one) and HDT $(1 \mathrm{mM})$ ) were selected based on the different head and tail groups, number of sulfur or thiol groups and chain length, as well as based on previous studies [13-15]. One of the key benefits of SAMs is that their simplicity of preparation; the electrode surface has to be just immersed in the SAM solution for a given period followed by washing with the same solvent [15]. 
The modification of the electrode with each SAM formed an organic assembly on the electrode surface that blocked the electron transfer between the electrode surface and the electroactive species in solution causing a signal reduction in the peak current. The block in the electron transfer for the electrodes modified with the different SAMs was studied using $\mathrm{Fe}(\mathrm{CN})_{6}{ }^{3-/ 4-}$ as redox probe (Figure S1 in Supplementary Data). For the same time of modification $(12 \mathrm{~h})$, the higher peak current diminution (97\%) was detected for the SAM composed of HDT. Therefore, among the tested SAMs, HDT-SAM was the best adsorbed and packed $[14,18,34]$ on the electrode surface. SAMs of alkanethiols on $\mathrm{Au}$ are one of the simplest way and best available surface modification for biosensors development since sulfur has strong affinity to $\mathrm{Au}$ and van der Waals inter-chain interactions ensure SAM tight packing and stability [13-15]. Moreover, since HDT has two - SH groups (one head group and a tail group), it will facilitate the immobilization of the AuNPs (Figure 1). Thus, the HDT/Au electrode was the selected to develop the immunosensor.

Afterward, the impact of the incubation time on the HDT-SAM formation was studied. Short incubation times were tested ( 1 and $2 \mathrm{~h}$ ) with the aim of achieving the electrode modification in the shorter time possible. Figure 2 shows the SWV recorded in the redox indicator $\left(\mathrm{Fe}(\mathrm{CN}){ }^{3-/ 4-}\right)$ for the $\mathrm{Au}$ electrode without modification and for the Au electrode modified with HDT-SAM for the tested times. As it can be seen in Figure 2, when an incubation time of $2 \mathrm{~h}$ was employed, a nearly total block of the electron transfer $(88 \%$ for $1 \mathrm{~h}$ and $96 \%$ for $2 \mathrm{~h}$, which is similar to the achieved with $12 \mathrm{~h}$, Figure S1) was obtained indicating that this duration is enough to form an organized and packed SAM of HDT on the Au electrode surface. Overall, this optimized incubation time

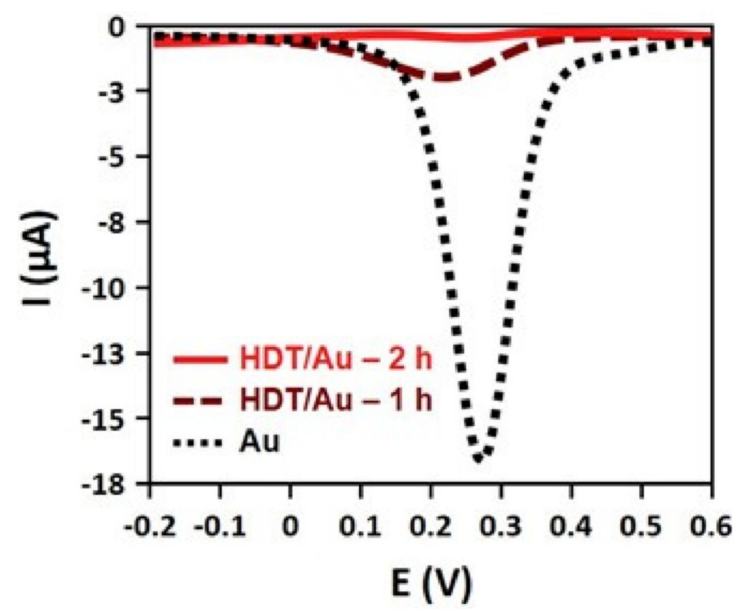

Fig. 2. Square-wave voltammograms recorded at a scan rate of $200 \mathrm{mV} \mathrm{s}^{-1}$ in $10 \mathrm{mM} \mathrm{Fe}(\mathrm{CN})_{6}{ }^{3-/ 4-}$ solution (in PBS $0.1 \mathrm{M} \mathrm{pH} \mathrm{7.4)}$ with the bare $(\mathrm{Au})$ and the modified electrode with hexanedithiol (HDT) employing $1 \mathrm{~h}(\mathrm{HDT} / \mathrm{Au}-1 \mathrm{~h})$ and $2 \mathrm{~h}(\mathrm{HDT} / \mathrm{Au}-2 \mathrm{~h})$ as incubation time. is short when compared with most data found in literature (from $30 \mathrm{~min}$ to $24 \mathrm{~h}$ ) [12,17,29,32,35-37].

\subsubsection{Characterization of AuNPs and AuNPs/HDT/Au Electrode}

The synthetized AuNPs presented a mean hydrodynamic diameter of $36 \mathrm{~nm}$ and an average zeta potential of $-35 \mathrm{mV}$, which suggest a stable suspension with low tendency to aggregation [38,39]. The AuNPs were also characterized by UV-VIS (Figure S2 in Supplementary Data), which spectra exhibited the typical band at $522 \mathrm{~nm}$ for AuNPs stabilized by citrate ions that confirms their low size [40-42].

Cyclic voltammograms were recorded in $10 \mathrm{mM}$ $\mathrm{Fe}(\mathrm{CN})_{6}{ }^{3-14-}$ solution (in PBS $0.1 \mathrm{M} \mathrm{pH} \mathrm{7.4)}$ at a scan rate of $50 \mathrm{mV} \cdot \mathrm{s}^{-1}$ employing the $\mathrm{Au}$ electrode without modification, the HDT/Au electrode and the AuNPs/HDT/Au electrode (Figure 3A), with the aim of determining if the modification with AuNPs allowed to recover the peak current obtained for the $\mathrm{Au}$ electrode before SAM modification. Accordingly, with previously reported works $[43,44]$, the modification of the HDT/Au electrode with the AuNPs enhanced the intensity of the peak. As Figure 3A shows, almost the same peak current was obtained for the Au electrode and for the AuNPs/HDT/ $\mathrm{Au}$ electrode. The successful electrode modification with AuNPs was also confirmed by SEM (Figure 3B-C) that showed an irregular surface with the AuNPs densely and well-distributed on the SAM-modified Au electrode; EDS characterization corroborated these findings (Figure 3D). Thus, electrochemical and optical techniques demonstrated the effective AuNPs/HDT/Au electrode modification.

\subsubsection{Antibody and Bovine Serum Albumin Immobilization}

Regarding the immobilization of the capture antibody (anti-PSA) on the AuNPs/HDT/Au electrode, several concentrations of antibody solution were tested (Figure S3 in Supplementary Data).

The antibody immobilization caused a large reduction of the $\mathrm{Fe}(\mathrm{CN})_{6}^{3-/ 4-}$ signal because of it forms a protein layer that blocked the electrode surface and therefore, hampered the electron transfer. The signal decreased with the increase of the antibody concentration. For $10 \mu \mathrm{g} \mathrm{mL}^{-1}$, the decrease of the signal was significant while for higher concentrations, the electrode surface seemed to be saturated. So, in order to assure a high surface coverage, $10 \mu \mathrm{g} \mathrm{mL}^{-1}$ was chosen as optimum antibody concentration.

After the immobilization of the antibody, a blocking step of the free surface sites of the anti-PSA/AuNPs/ HDT/Au electrode was carried out in order to avoid nonspecific binding of the PSA onto the electrode surface. This blocking step consisted of immobilizing BSA onto the electrode surface. BSA immobilization generated 

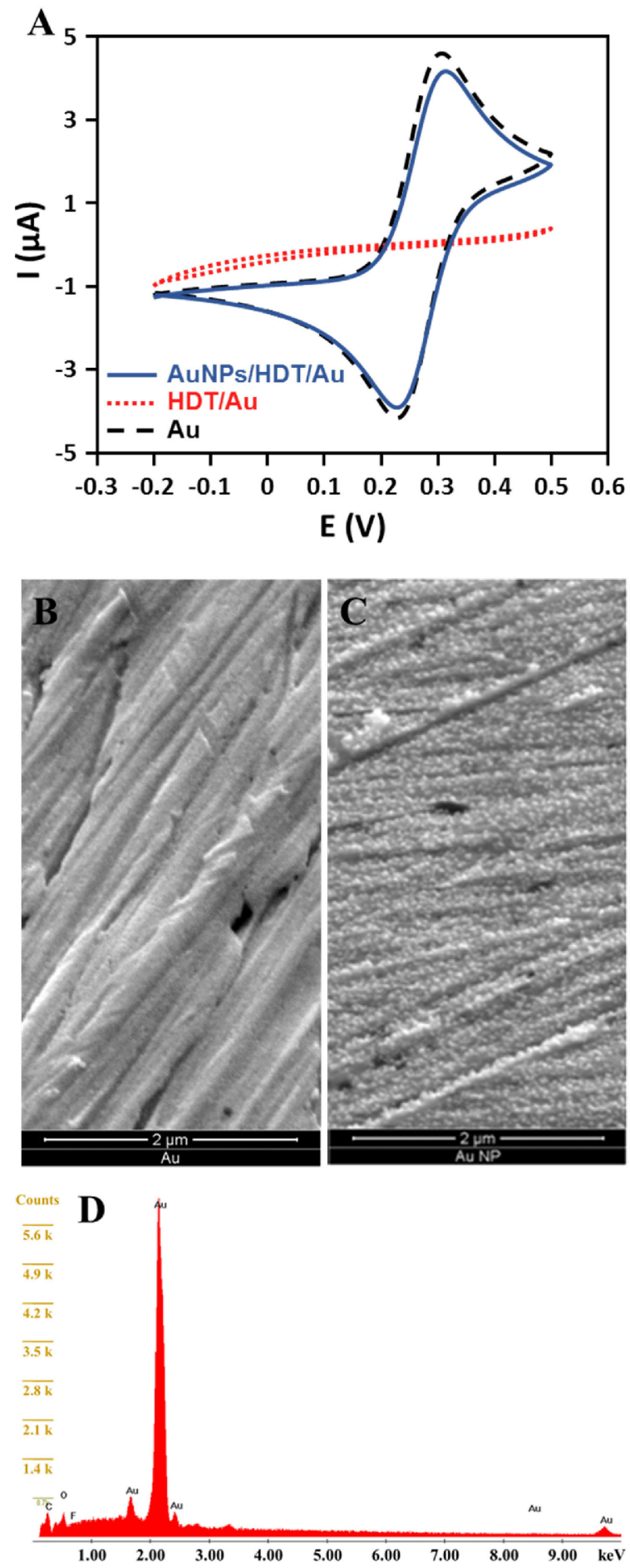

Fig. 3. (A) Cyclic voltammograms recorded in $10 \mathrm{mM}$

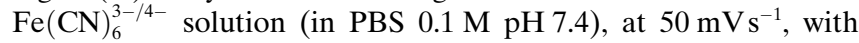
the bare electrode $(\mathrm{Au})$, the electrode modified with hexanedithiol (HDT/Au) and AuNPs (AuNPs/HDT/Au). (B,C) Scanning electron microscopy images of the bare Au electrode (B) and AuNPs/HDT/Au electrode (C). (D) Energy dispersive spectrum of the AuNPs/HDT/Au electrode.

another insulating protein layer on the anti-PSA/AuNPs/ $\mathrm{HDT} / \mathrm{Au}$ electrode, hindering the electron transfer. This step caused $28 \%$ of peak current reduction $v$ s. the peak current for anti-PSA/AuNPs/HDT/Au electrode (when SWV is used) (Figure S4). These results proved that both, anti-PSA and BSA, were successfully immobilized on the AuNPs/HDT/Au electrode.

\subsection{Electroanalytical Performance of the Immunosensor}

Applying the optimized immunosensor (BSA/anti-PSA/ $\mathrm{AuNPs} / \mathrm{HDT} / \mathrm{Au}$ ), the peak current decreased in the presence of increased concentrations of PSA, due to the block of the electron transport as a result of the capture of the PSA by its antibody (Figure 4). Simultaneously, this capture also promoted a slight negative shift of the peak potential, when the antigen concentrations were augmented, due to the modification of the interface properties of the biosensor surface. Still, the peak current reduction showed a linear increase vs. $\log$ of PSA concentrations in the range between 0.2 and $200 \mathrm{ng} \mathrm{mL}^{-1}$ (Figure 4). The calibration curve presented wide linearity, good sensitivity $\left(\right.$ slope $=22.7 \%$ reduction $\mathrm{mL} \mathrm{ng}^{-1}$ ), data
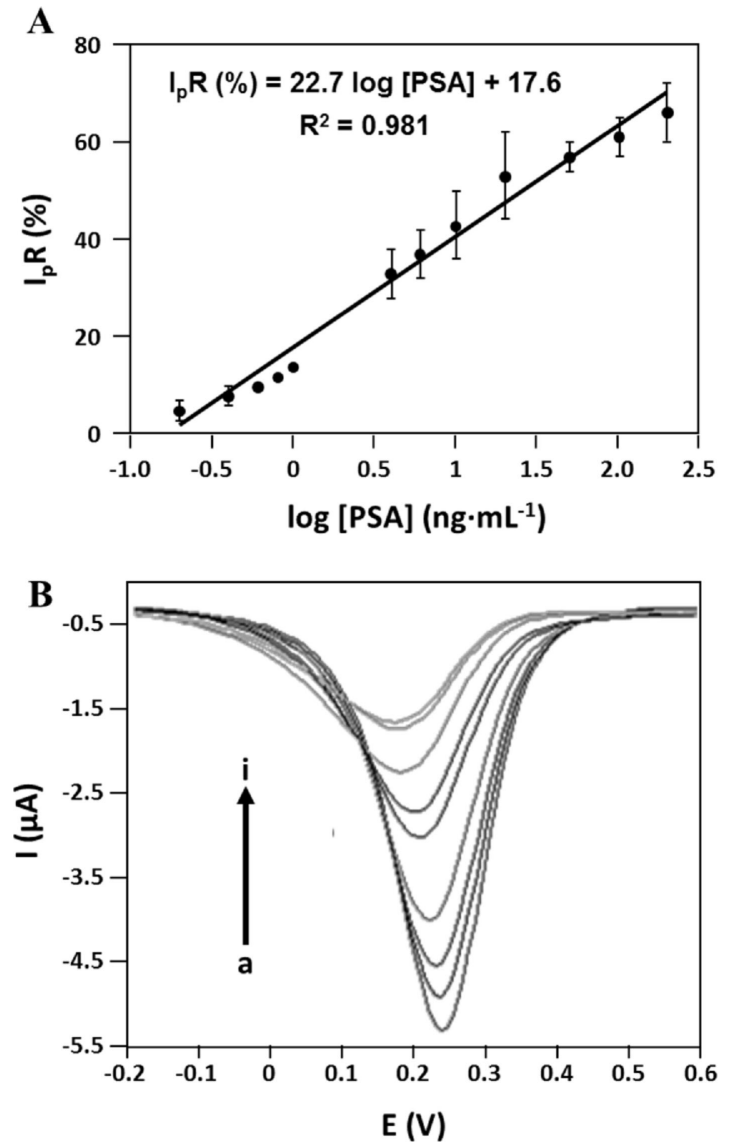

Fig. 4. Calibration data for the immunosensor based on the square-wave cathodic peak current reduction $\left(\mathrm{I}_{\mathrm{p}} \mathrm{R} ; \%\right)$ using $10 \mathrm{mM} \mathrm{Fe}(\mathrm{CN})_{6}^{3-/ 4-}$ solution (in PBS $0.1 \mathrm{M} \mathrm{pH} \mathrm{7.4)}$ ) as electroactive indicator: (A) Calibration plot $(0.2,0.4,0.6,0.8,1,4,6,10$, $20,50,100,200 \mathrm{ng} \mathrm{mL}^{-1}$ of PSA); error bars correspond to the standard deviation of 6 measurements; (B) Representative square-wave voltammograms ( 0.4 to $50 \mathrm{ng} \mathrm{mL}^{-1}$ of PSA). 
Table 1. Comparison of analytical properties of different electrochemical immunosensors for PSA detection.

\begin{tabular}{|c|c|c|c|c|c|}
\hline Transducer & Construction & Detection & $\begin{array}{l}\text { Concentration } \\
\text { range } \\
\left(\mathrm{ng} \mathrm{mL}^{-1}\right)\end{array}$ & $\begin{array}{l}\mathrm{LOD} \\
\left(\mathrm{ng} \mathrm{mL} \mathrm{mL}^{-1}\right)\end{array}$ & Ref. \\
\hline Gold electrode & HDT SAM/AuNPs/anti-PSA. Label free. & SWV & $0.2-200$ & 0.01 & $\begin{array}{l}\text { This } \\
\text { work }\end{array}$ \\
\hline $\begin{array}{l}\text { 8-channel } \\
\text { SPCEs }\end{array}$ & $\begin{array}{l}\text { Streptavidin-coated magnetic beads and biotinylated anti-PSA. } \\
\text { Sandwich assay. HRP as label. }\end{array}$ & Amperometry & $5-100$ & 1.86 & {$[27]$} \\
\hline Gold electrode & $\begin{array}{l}\text { Cysteine SAM/Anti-PSA. Sandwich assay. scFv detection anti- } \\
\text { body-conjugated PtNPs. Label free. }\end{array}$ & Amperometry & $1-30$ & 0.03 & {$[28]$} \\
\hline Gold electrode & $\begin{array}{l}\text { OEGMA-co-GMA/AuNPs/Anti-PSA. Sandwich assay. Detection } \\
\text { antibody- conjugated SiNPs. Label free. }\end{array}$ & DPV & $0.005-1000$ & 0.002 & [29] \\
\hline Gold electrode & CYS SAM/Fc cored PAMAM/anti-PSA. Label free. & DPV & $0.01-100$ & 0.001 & {$[32]$} \\
\hline $\begin{array}{l}\text { Glassy carbon } \\
\text { electrode }\end{array}$ & $\begin{array}{l}\text { Silver hybridized mesoporous silica nanoparticles/Anti-PSA. Label } \\
\text { free. }\end{array}$ & $\mathrm{CV}$ & $0.05-50$ & 0.015 & {$[45]$} \\
\hline $\begin{array}{l}\text { Glassy carbon } \\
\text { electrode }\end{array}$ & SP-modified rGO nanosheets/anti-PSA. Label free. & DPV & $0.1-5 ; 5-80$ & 0.053 & [46] \\
\hline $\begin{array}{l}\text { Pencil graphite } \\
\text { electrode }\end{array}$ & $\begin{array}{l}\text { Peptide nanotube/AuNPs/PANI modified electrode. Sandwich } \\
\text { assay. HRP as label. }\end{array}$ & Amperometry & $1-100$ & 0.68 & [47] \\
\hline $\begin{array}{l}\text { 3D origami pa- } \\
\text { per SPCE }\end{array}$ & $\begin{array}{l}\mathrm{MnO}_{2} \text { nanowires electrodeposited on WE with AuNPs layer. } \\
\text { Sandwich assay. GOX and detection antibodies attached on carbon } \\
\text { nanospheres. }\end{array}$ & DPV & $0.005-100$ & 0.0012 & {$[48]$} \\
\hline Gold electrode & $\begin{array}{l}\text { MWCNTs/AuNPs/anti-PSA. Sandwich assay. HRP molecules and } \\
\text { detection antibody attached on MWCNTs. }\end{array}$ & SWV & $0.001-10$ & 0.0004 & [49] \\
\hline $\begin{array}{l}\text { Paper-based } \\
\text { carbon elec- } \\
\text { trode }\end{array}$ & $\begin{array}{l}\text { Anti-PSA on gold nanorods modified paper electrode. Sandwich } \\
\text { assay. Porous zinc oxide spheres-AgNPs as label. }\end{array}$ & Amperometry & $0.004-60$ & 0.0015 & {$[50]$} \\
\hline Gold electrode & 6-mercapto- $\beta$-cyclodextrin SAM/anti-PSA. Label free. & DPV & $0.001-1$ & 0.0003 & [51] \\
\hline Gold SPE & TCNQ/Cu-MOF/anti-PSA. Label free. & Conductometry & $0.1-100$ & 0.06 & {$[52]$} \\
\hline
\end{tabular}

SPCE: screen-printed carbon electrode; SPE: screen-printed electrode; LSV: linear sweep voltammetry; CV: cyclic voltammetry; WE: working electrode; PtNPs: platinum nanoparticles; Fc: ferrocene, PAMAM: polyamidiamine dendrimers; PANI: polyaniline; rGO: reduced graphene oxide; SP: silk peptide; OEGMA-co-GMA: (oligo/ethylene glycol)methacrylate-co-glycidyl methacrylate; AgNPs: silver nanoparticles; SiNPs: silica nanoparticles; MWCNTs: multiwalled carbon nanotubes; TCNQ: tetracyanoquinodimethante; MOF: metal organic framework.

well-distributed with low standard deviation $(<13 \%)$ and a correlation coefficient $(\mathrm{r})$ of 0.990 . The limit of detection (LOD) was calculated as the lowest concentration of PSA that gives a peak current three times higher than the standard deviation of the analytical signal obtained in absence of PSA under identical conditions [53]. The LOD value thus obtained was $0.01 \mathrm{ng} \mathrm{mL}^{-1}$ while the limit of quantification (LOQ, ten times the standard deviation of

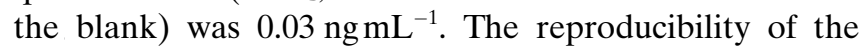
immunosensor was also evaluated using six different modified electrodes and a RSD of $5 \%$ was attained for $50 \mathrm{ng} \mathrm{mL} \mathrm{m}^{-1}$ PSA concentration. The reached broad concentration range, low LOD and the good reproducibility show that this simple immunosensor presents appropriate analytical features for PSA detection.

Table 1 displays the electroanalytical characteristics of recent reported electrochemical immunosensor for PSA detection and those of the developed immunosensor. As it can be seen, the proposed immunosensor improves the width of the concentration range and the LOD in comparison with some of the recent reported sensors $[27,28,45-47]$. Although other immunosensors show lower LOD that the achieved in this work [29,32,48-51] (Table 1), it has to be considered that the construction of these biosensors involves more complex schemes and higher costs (since more materials, reagents and/or steps are needed). Moreover, from a clinical point of view, a wider concentration range or a LOD lower that the achieved by our immunosensor have no real utility (since the clinical threshold level is $2.5-4 \mathrm{ng} \mathrm{mL}^{-1}$ ). Therefore, the electroanalytical characteristics combined with the simplicity of the proposed immunosensor make this approach an interesting tool for PSA determination; even more considering the label-free detection, which avoids the need of expensive enzyme-linked antibody for recognition or functionalized nanomaterials for signal augmentation, decreasing the design complexity and cost.

The reusability of the biosensor was additionally assessed. The immunosensor, once used for $10 \mathrm{ng} \mathrm{mL} L^{-1}$ PSA detection, was immersed in $0.1 \mathrm{M}$ glycine- $\mathrm{HCl}$ solution $\mathrm{pH} 3$ for 20 minutes with the aim of breaking the antibody-antigen linkage, and then it was applied for PSA detection over again. It retained $86 \%$ of its initial signal after 12 cycles of utilizations (measurement always followed by regeneration), demonstrating the success of the process. This feature is clearly an advantage when compared to the previously reported biosensors for PSA 
detection that are usually designed to be used only one time $[32,45-47,49]$.

\section{Conclusions}

A simple immunosensor based on a modified gold electrode has been developed for label-free voltammetric analysis of PSA. The construction of the proposed biosensor consists of a HDT self-assembled monolayer forming an organized and packed layer on the surface of a gold electrode, which enabled a fast and successful modification with AuNPs. These nanoparticles, due to their excellent conducting characteristics, promoted the electronic transfer between the mediator and the electrode surface amplifying the signal of the electrochemical reaction. Thus, an immunosensor with low detection limit, broad linearity range and suitable reproducibility was achieved. The main advantages of the proposed immunosensor are its simplicity and low-cost construction, as well as the required relatively inexpensive instrumentation. The linear range achieved makes this immunosensor useful for PSA determination in clinical samples.

\section{Acknowledgements}

The authors are grateful for financial support from the European Union (FEDER funds through COMPETE) and National Funds (FCT) through projects UID/QUI/ 50006/2013 and UID/CTM/50011/2013. The authors also thank financial support by Norte Portugal Regional Operational Programme (NORTE 2020), under the PORTUGAL 2020 Partnership Agreement, through the European Regional Development Fund (ERDF): projects Norte-01-0145-FEDER-000011, Norte-01-0145-FEDER000024 and POCI-01-0145-FEDER-007679.

\section{References}

[1] World Heal. Organ. Int. Agency Res. Cancer. Glob. Cancer Obs. (GCO). http//gco.iarc.fr/ (accessed 18.06.18) n.d.

[2] C. K. Zhou, D. P. Check, J. Lortet-Tieulent, M. Laversanne, A. Jemal, J. Ferlay, F. Bray, M. B. Cook, S. S. Devesa, Int. J. Cancer 2016, 138, 1388-1400.

[3] A. Barve, W. Jin, K. Cheng, J. Controlled Release 2014, 187, 118-132.

[4] E. C. Rama, A. Costa-García, Electroanalysis 2016, 28, 1700-1715.

[5] K. C. Cary, M. R. Cooperberg, Ther. Adv. Urol. 2013, 5, 318329.

[6] X. Sun, C. Lei, L. Guo, Y. Zhou, Microchim. Acta 2016, 183, 2385-2393.

[7] A. H. Khan, E. Sadroddiny, Mol. Cell. Probes 2016, 30, 106112.

[8] E. Burcu Bahadir, M. Kemal Sezgintürk, Talanta 2015, 132, 162-174.

[9] C. Kokkinos, A. Economou, M. I. Prodromidis, $\operatorname{Tr} A C$ Trends Anal. Chem. 2016, 79, 88-105.

[10] F. Arduini, L. Micheli, D. Moscone, G. Palleschi, S. Piermarini, F. Ricci, G. Volpe, TrAC Trends Anal. Chem. 2016, 79, 114-126.
[11] D. G. A. Cabral, E. C. S. Lima, P. Moura, R. F. Dutra, Talanta 2016, 148, 209-215.

[12] X. Liu, W. Li, L. Li, Y. Yang, L. Mao, Z. Peng, Sens. Actuators B Chem. 2014, 191, 408-414.

[13] P. Carneiro, J. Loureiro, C. Delerue-Matos, S. Morais, M. do Carmo Pereira, Sens. Actuators B Chem. 2017, 239, 157-165.

[14] C. Vericat, M. E. Vela, G. Benitez, P. Carro, R. C. Salvarezza, Chem. Soc. Rev. 2010, 39, 1805-1834.

[15] N. K. Chaki, K. Vijayamohanan, Biosens. Bioelectron. 2002, $17,1-12$.

[16] M. Ç. Canbaz, Ç. S. Şimşek, M. K. Sezgintürk, Anal. Chim. Acta 2014, 814, 31-38.

[17] A. M. Mahmoud, T. Tang, D. Jed Harrison, W. E. Lee, A. B. Jemere, Biosens. Bioelectron. 2014, 56, 328-333.

[18] V. Y. Kutsenko, Y. Y. Lopatina, L. Bossard-Giannesini, O. A. Marchenko, O. Pluchery, S. V. Snegir, Nanotechnology 2017, 28, 235603.

[19] J. M. Pingarrón, P. Yáñez-Sedeño, A. González-Cortés, Electrochim. Acta 2008, 53, 5848-5866.

[20] S. Guo, E. Wang, Anal. Chim. Acta 2007, 598, 181-192.

[21] J. Fei, W. Dou, G. Zhao, Microchim. Acta 2015, 182, 22672275.

[22] E. C. Rama, M. B. González-García, A. Costa-García, Sens. Actuators B Chem. 2014, 201, 567-571.

[23] R. C. B. Marques, S. Viswanathan, H. P. A. Nouws, C. Delerue-Matos, M. B. González-García, Talanta 2014, 129, 594-599.

[24] V. Escamilla-Gómez, D. Hernández-Santos, M. B. GonzálezGarcía, J. M. Pingarrón-Carrazón, A. Costa-García, Biosens. Bioelectron. 2009, 24, 2678-2683.

[25] G. K. Ahirwal, C. K. Mitra, Biosens. Bioelectron. 2010, 25, 2016-2020.

[26] K. Matsumoto, N. Konishi, Y. Hiasa, E. Kimura, Y. Takahashi, K. Shinohara, T. Samori, Clin. Chim. Acta 1999, 281, 57-69.

[27] J. Biscay, M. B. González García, A. C. García, Electroanalysis 2015, 27, 2773-2777.

[28] E. Spain, S. Gilgunn, S. Sharma, K. Adamson, E. Carthy, R. O'Kennedy, R. J. Forster, Biosens. Bioelectron. 2016, 77, 759-766.

[29] S. Rafique, W. Bin, A. S. Bhatti, Bioelectrochemistry 2015, 101, 75-83.

[30] J. H. Lee, J. E. R. Rho, T. H. D. Rho, J. G. Newby, Biosens. Bioelectron. 2010, 26, 377-382.

[31] K. Ito, W. Nishimura, M. Maeda, K. Gomi, S. Inouye, H. Arakawa, Anal. Chim. Acta 2007, 588, 245-251.

[32] E. Çevik, Ö. Bahar, Ş. Mehmet, M. F. Abas, Biosens. Bioelectron. 2016, 86, 1074-1079.

[33] J. Turkevich, P. C. Stevenson, J. Hillier, Discuss. Faraday Soc. 1951, 11, 55-75.

[34] D. Qu, B.-C. Kim, C.-W. J. Lee, M. Ito, H. Noguchi, K. Uosaki, J. Phys. Chem. C 2010, 114, 497-505.

[35] A. Ahmad, E. Moore, Analyst 2012, 137, 5839.

[36] P. Jolly, N. Formisano, J. Tkáč, P. Kasák, C. G. Frost, P. Estrela, Sens. Actuators B Chem. 2015, 209, 306-312.

[37] S. Chunta, J. Suk-Anake, K. Chansiri, C. Promptmas, Analyst 2014, 139, 4586.

[38] W. Wang, X. Ding, Q. Xu, J. Wang, L. Wang, X. Lou, Colloids Surf. B Biointerfaces 2016, 148, 541-548.

[39] A. Majzik, R. Patakfalvi, V. Hornok, I. Dékány, Gold Bull. 2009, 42, 113-123.

[40] I. Almeida, V. C. Ferreira, M. F. Montemor, L. M. Abrantes, A. S. Viana, Electrochim. Acta 2012, 83, 311-320.

[41] S. Link, M. A. El-Sayed, J. Phys. Chem. B 1999, 103, 4212.

[42] V. C. Ferreira, A. F. Silva, L. M. Abrantes, J. Phys. Chem. C 2010, 114, 7710-7716. 
[43] J. N. Chazalviel, P. Allongue, J. Am. Chem. Soc. 2011, 133, 762-764.

[44] J. B. Shein, L. M. H. Lai, P. K. Eggers, M. N. Paddon-Row, J. J. Gooding, Langmuir 2009, 25, 11121-11128.

[45] H. Wang, Y. Zhang, H. Yu, D. Wu, H. Ma, H. Li, B. Du, Q. Wei, Anal. Biochem. 2013, 434, 123-127.

[46] Y. Wang, Y. Qu, G. Liu, X. Hou, Y. Huang, W. Wu, K. Wu, C. Li, Microchim. Acta 2015, 182, 2061-2067.

[47] T. Vural, Y. T. Yaman, S. Ozturk, S. Abaci, E. B. Denkbas, J. Colloid Interface Sci. 2018, 510, 318-326.

[48] L. Li, J. Xu, X. Zheng, C. Ma, X. Song, S. Ge, J. Yu, M. Yan, Biosens. Bioelectron. 2014, 61, 76-82.

[49] R. Akter, M. A. Rahman, C. K. Rhee, Anal. Chem. 2012, 84, 6407-6415.

[50] G. Sun, H. Liu, Y. Zhang, J. Yu, M. Yan, X. Song, W. He, New J. Chem. 2015, 39, 6062-6067.

[51] H. Deng, J. Li, Y. Zhang, H. Pan, G. Xu, Anal. Chim. Acta 2016, 926, 48-54.

[52] S. K. Bhardwaj, A. L. Sharma, N. Bhardwaj, M. Kukkar, A. A. S. Gill, K. H. Kim, A. Deep, Sens. Actuators B Chem. 2017, 240, 10-17.

[53] J. N. Miller, J. C. Miller, Statistics and Chemometrics for Analytical Chemistry, Pearson Prentice Hall, United Kingdom, 2005. 